\title{
Improvement of Red Rice Yield by Changing from Conventional to Aerobic Irrigation Systems Intercropped with Soybean at Different Dates
}

\author{
Wayan Wangiyana $^{1 *}$, Nihla Farida ${ }^{1}$, Akhmad Zubaidi $^{1}$, Ni Wayan Sri Suliartini ${ }^{1}$ \\ ${ }^{1}$ Department of Agronomy, Faculty of Agriculture, University of Mataram, Mataram, NTB, Indonesia \\ *Corresponding author email: w.wangiyana@unram.ac.id
}

\begin{abstract}
Previous studies reported that intercropping rice with legume crops under aerobic systems increased growth and yield of rice compared with monocropped rice. This study aimed to examine the effects of rice cultivation techniques and patterns of rows on growth and yield of red rice with special objective to examine if intercropping red rice with soybean relay-planted between double or triple rows of rice on raised-beds under aerobic irrigation system can produce higher yield than the conventional one. The experiment was conducted in Narmada (West Lombok, Indonesia), arranged according to Split Plot design with two treatment factors, i.e. rice row patterns as the main plots $(P 1=$ double, $P 2=$ triple rows $)$ and techniques of rice cultivation ( $T c=$ conventional rice, $T 0=$ irrigated aerobic rice system $(A R S)$ without intercropping; $T 1=$ relay-planting soybean 1 week, $T 2=2$ weeks, $T 3=3$ weeks after seeding the pre-germinated red rice seeds). Results indicated that between the two treatment factors, techniques of growing rice resulted in significant effects on more variables compared with the patterns of rice rows, but there were significant interaction effects on leaf number per clump at anthesis and grain yield per clump. Based on the main effects, tiller number, filled panicle number and grain yield per clump and harvest index were significantly higher on red rice plants grown in irrigated aerobic systems intercropped with soybean compared with those in aerobic monocropped or conventional systems, with the highest grain yield average of $53.76 \mathrm{~g} / \mathrm{clump}$ in T3, 29.04 $\mathrm{g} / \mathrm{clump}$ in TO and only $17.45 \mathrm{~g} / \mathrm{clump}$ in Tc treatment, and based on the interaction effects, the highest average of grain yield was on red rice plants in the T3 treatment under triple-row pattern $(57.58 \mathrm{~g} / \mathrm{clump})$ and the lowest was on conventional plot (Tc) under double-row pattern (16.53 g/clump).
\end{abstract}

Keywords - Soybean, red rice, intercropping, aerobic irrigation systems, comventional, row patterns.

\section{INTRODUCTION}

Rice (Oryza sativa L.) is normally cultivated under the conventional technique that is referred as to paddy rice, in which rice is grown on puddled and flooded soil. Therefore, the root systems are in an anaerobic soil condition. In contrast, under aerobic rice systems, rice is grown on non-puddled, non-flooded and non-saturated soil $[1,2]$. One of the advantages of growing rice under aerobic systems is that rice plants can be grown together or intercropped with a legume crop such as soybean [3].

Intercropping cereal crops, such as rice and maize with legume crops such as peanut and soybean was reported to provide some advantages for both types of crops, but in more specially for the cereal crops. Inal et al. [4] found that the rhizosphere of maize-peanut intercrop contains higher concentration of several macro and micro nutrients compared with in the rhizosphere of maize or peanut in monocrop. Chu et al. [5] also reported significant $\mathrm{N}$ transfer from peanut to rice in intercropping system under aerobic conditions. In addition, Fujita et al. [6] also reported $\mathrm{N}$ transfer from soybean to sorghum in intercropping system, and the amount of $\mathrm{N}$ transfer was higher as the planting distance was closer.
Leaves of the red rice plants grown together with soybean in pot culture under aerobic irrigation systems were also much greener than those grown in monocrop [3], which also indicated some $\mathrm{N}$ transfer from soybean to rice plants. The red rice plants grown in intercropping with soybean on raised-bed under aerobic irrigation system was also reported to show better growth and to produce higher grain yield [7] and higher anthocyanin contents in the rice grains [8], when compared with those grown on the monocrop beds. Wangiyana et al. [9] also reported that additive intercropping with peanut relay-planted between double or triple rows of rice either one or two or three weeks after planting the pre-germinated seeds of rice significantly increased panicle number and grain yield of red rice per clump.

In addition, relay-planting dates of the peanut plants relative to planting dates of the rice plants also showed significant effects on panicle number and grain yield of the red rice per clump, in which grain yield per clump was higher on the red rice plants relay-planted with peanut at two or three weeks compared with one week after planting the pre-germinated seeds of the red rice [9]. Arifuddin et al. [10] also reported significant effects of relay-planting dates of legume crops (peanut, soybean, mungbean) 
relative to planting dates of red rice pre-germinated seeds in pot culture on grain yield of the red rice plants, in which grain yield was higher on rice plants relay-planted with the legume crops at two or three or four weeks compared with one week after planting red rice. However, grain yield of the red rice per pot was not significantly different among rice plants relay-planted with the legume crops at two or three or four weeks after planting the red rice seeds [10].

This study aimed to examine the effects of relayplanting dates of soybean between double or triple rows of red rice plants grown on raised-beds under an aerobic irrigation system. It was also aimed to examine the potential of these aerobic rice systems in increasing yield of the red rice compared with those grown under the conventional technique of rice cultivation.

\section{MATERIALS AND METHODS}

The field experiment in this study was conducted on paddy field in the Experimental Farm of the Faculty of Agriculture, University of Mataram, located in Narmada (Lombok, Indonesia) from June to October 2016. The experiment was arranged according to Split Plot design, testing two treatment factors, namely: the patterns of rice rows $(\mathrm{P})$ as the main plots $(\mathrm{P} 1=$ double row, $\mathrm{P} 2=$ triple row), and techniques ( $\mathrm{T}$ ) of rice cultivation as the subplots $(\mathrm{Tc}=$ conventional (flooded) rice; $\mathrm{T} 0=$ irrigated aerobic rice system (ARS) on raised-beds without intercropping, $\mathrm{T} 1=$ ARS intercropped with soybean ("Anjasmoro" variety) relay-planted at $1, \mathrm{~T} 2=2, \mathrm{~T} 3=3$ weeks after planting (WAP) pre-germinated rice seeds). The conventional rice systems were established in each block surrounded with a dike to maintain $5-10 \mathrm{~cm}$ standing water and rice seedlings (seeded on the same day of planting aerobic rice) were transplanted to the conventional plots at 3 weeks old, while the aerobic rice plants were grown on raised-beds of $25 \mathrm{~cm}$ height, and irrigation water was flowed through the furrow surrounding the raised-beds by maintaining the surface of the irrigation water $15 \mathrm{~cm}$ lower than the surface of the raised-beds. Each treatment combination was made in three blocks. The details of the treatments of aerobic irrigation systems and the implementation of the experiment were as described in Farida et al. [11], except for the legume crop used in this study was soybean instead of peanut in previous report [11].

The observation variables include plant height, leaf number and tiller number at 12 WAP, panicle number, dry straw weight and grain yield per clump, weight of 100 grains, and harvest index, which was based on Wangiyana et al. [9]. Data were analyzed with analysis of variance
(ANOVA) and Tukey's HSD at 5\% level of significance using CoStat for Windows ver. 6.303 and correlation analysis using Minitab for Windows Rel. 13.

\section{RESULTS AND DISCUSSION}

The summary of ANOVA results in Table 1 shows that between the two treatment factors tested, techniques of rice cultivation had more significant effects on growth and yield of red rice compared with the effects of row patterns, but there were significant interaction effects on grain yield and leaf number per clump at anthesis.

Based on the main effects in Table 1, except for the weight of 100 dry grains, all other observation variables were affected by the techniques of rice cultivation, especially between the conventional rice and aerobic rice on raised-beds intercropped with soybean, in which yield and yield components of the red rice were on average significantly lower on the red rice plants cultivated under the conventional technique. As can be seen from Table 1, grain yield per clump is the most significantly different between techniques of growing rice, being the highest average is in the aerobic red rice plants intercropped with soybean plants relay-planted three weeks after seeding the pre-germinated red rice seeds (T3 treatment).

This highest average of grain yield per clump in the T3 treatment is also supported by the highest leaf and tiller number per clump at anthesis, filled-panicle number and harvest index. The highest harvest index means that the highest proportion of the biomass that was partitioned to the growing seeds during the seed-filling stage, and with the highest filled-panicle number supported with the highest leaf number at anthesis, these conditions would result in the highest grain yield per clump in the red rice plants in T3 treatment. These observation variables had positive and significant correlation coefficients with grain yield per clump, and among those observation variables, harvest index showed the highest correlation coefficient ( $\mathrm{r}$ $=+0.961$ ) with grain yield per clump (Table 2).

In relation to leaf number, the highest average at anthesis was in the T3 treatment, which means that the average number of green leaves at anthesis was in the T3 treatment, in which the red rice plants were grown on raised-beds intercropped with soybean relay-planted three weeks after seeding the pre-germinated rice seeds. Wangiyana et al. [3] also reported that red rice plants grown together in one pot with soybean showed much greener leaves than those grown in monocrop. Higher number of green leaves after anthesis would increase photosynthesis during the grain filling process. 
Table 1: Summary of ANOVA results for the effects of the treatment factors on all observation variables

\begin{tabular}{|c|c|c|c|c|c|c|c|c|}
\hline Treatments: & $\begin{array}{c}\text { Plant height } \\
\text { (cm) }\end{array}$ & $\begin{array}{c}\text { Leaf number } \\
\text { per clump }\end{array}$ & $\begin{array}{c}\text { Tiller } \\
\text { number per } \\
\text { clump }\end{array}$ & $\begin{array}{c}\text { Panicle } \\
\text { number per } \\
\text { clump }\end{array}$ & $\begin{array}{c}\text { Weight of } \\
100 \text { grains } \\
\text { (g) }\end{array}$ & $\begin{array}{c}\text { Grain yield } \\
\text { (g/clump) }\end{array}$ & $\begin{array}{c}\text { Dry straw } \\
\text { weight } \\
\text { (g/clump) }\end{array}$ & $\begin{array}{c}\text { Harvest } \\
\text { index }(\%)\end{array}$ \\
\hline \multicolumn{9}{|c|}{ Rice cultivation techniques: } \\
\hline Tc: conventional rice & $85.33 \mathrm{~b}$ & $46.08 \mathrm{c}$ & $16.94 \mathrm{~b}$ & $14.00 \mathrm{~b}$ & $2.53 \mathrm{a}$ & $17.45 \mathrm{e}$ & $50.30 \mathrm{c}$ & $25.59 c^{1)}$ \\
\hline $\mathrm{T}_{0}$ : ARS monocrop & $103.30 \mathrm{a}$ & $97.73 a b$ & $23.43 \mathrm{a}$ & $16.50 \mathrm{~b}$ & $2.37 \mathrm{a}$ & $29.04 \mathrm{~d}$ & $51.10 \mathrm{bc}$ & $36.22 b$ \\
\hline $\mathrm{T}_{1}:$ ARS+soybean 1wk & $106.77 \mathrm{a}$ & $95.80 \mathrm{~b}$ & $25.17 \mathrm{a}$ & $21.00 \mathrm{a}$ & $2.37 \mathrm{a}$ & $43.83 \mathrm{c}$ & $53.66 \mathrm{abc}$ & $45.13 \mathrm{a}$ \\
\hline$T_{2}:$ ARS+soybean 2wk & $107.70 \mathrm{a}$ & $93.40 \mathrm{~b}$ & $26.70 \mathrm{a}$ & $22.25 \mathrm{a}$ & $2.44 \mathrm{a}$ & $50.19 b$ & $59.14 \mathrm{a}$ & $45.87 \mathrm{a}$ \\
\hline$T_{3}:$ ARS+soybean 3wk & $103.93 \mathrm{a}$ & $108.10 \mathrm{a}$ & $28.33 \mathrm{a}$ & $21.67 \mathrm{a}$ & $2.37 \mathrm{a}$ & $53.76 \mathrm{a}$ & $58.81 \mathrm{ab}$ & $47.74 \mathrm{a}$ \\
\hline HSD 5\% & 8.86 & 12.03 & 4.92 & 4.17 & ns & 3.07 & 7.80 & $3.45^{2)}$ \\
\hline \multicolumn{9}{|l|}{ Rice row-patterns: } \\
\hline $\mathrm{P}_{1}$ : double-row & $99.85 \mathrm{~b}$ & $95.12 \mathrm{a}$ & $24.45 \mathrm{a}$ & $18.53 \mathrm{a}$ & $2.43 \mathrm{a}$ & $37.36 \mathrm{a}$ & $53.23 \mathrm{a}$ & $39.84 \mathrm{a}$ \\
\hline$P_{2}$ : triple-row & $102.96 \mathrm{a}$ & $81.33 \mathrm{~b}$ & $23.78 \mathrm{a}$ & $19.63 \mathrm{a}$ & $2.40 \mathrm{a}$ & $40.35 \mathrm{a}$ & $55.98 \mathrm{a}$ & $40.37 \mathrm{a}$ \\
\hline HSD $5 \%$ & 2.16 & 7.53 & ns & ns & ns & ns & ns & ns 2) \\
\hline Interactions: & ns & $* * *$ & ns & ns & ns & ** & ns & ns 2) \\
\hline
\end{tabular}

1) Mean in each column with same letters indicates non-significant differences between levels of a treatment factor.

2) ANOVA results: $\mathrm{ns}=$ non-significant; $* *, * * *=$ significant at $p$-value $<0.01$ and $p$-value $<0.001$, respectively.

Table 2: Correlation coefficients between observation variables and their p-values

\begin{tabular}{|c|c|c|c|c|c|c|c|}
\hline Observation variables & Plant height & Leaf number & $\begin{array}{c}\text { Tiller } \\
\text { number }\end{array}$ & $\begin{array}{l}\text { Panicle } \\
\text { number }\end{array}$ & $\begin{array}{l}\text { Weight of } 100 \\
\text { grains }\end{array}$ & $\begin{array}{c}\text { Straw dry } \\
\text { weight }\end{array}$ & Grain yield \\
\hline Leaf number per clump & 0.604 & & & & & & \\
\hline$p$-value & 0.000 & & & & & & \\
\hline Tiller number per clump & 0.712 & 0.738 & & & & & \\
\hline$p$-value & 0.000 & 0.000 & & & & & \\
\hline Panicle number per clump & 0.638 & 0.600 & 0.803 & & & & \\
\hline$p$-value & 0.000 & 0.000 & 0.000 & & & & \\
\hline Weight of 100 grains & -0.290 & -0.260 & -0.133 & -0.090 & & & \\
\hline$p$-value & 0.120 & 0.165 & 0.485 & 0.641 & & & \\
\hline Weight of dry straw & 0.557 & 0.174 & 0.502 & 0.496 & -0.022 & & \\
\hline$p$-value & 0.001 & 0.358 & 0.005 & 0.005 & 0.909 & & \\
\hline Dry grain yield per clump & 0.724 & 0.590 & 0.803 & 0.828 & -0.139 & 0.675 & \\
\hline$p$-value & 0.000 & 0.001 & 0.000 & 0.000 & 0.465 & 0.000 & \\
\hline Harvest index & 0.745 & 0.715 & 0.826 & 0.842 & -0.167 & 0.485 & 0.961 \\
\hline$p$-value & 0.000 & 0.000 & 0.000 & 0.000 & 0.378 & 0.007 & 0.000 \\
\hline
\end{tabular}

Leaf number at anthesis and grain yield per clump also showed a significant interaction between the two treatments factors, which means that the differences in leaf number and grain yield of the red rice between patterns of rice rows depend on the techniques of rice cultivation practiced. From Fig. 1 it can be seen that average number of green leaves per clump was very low in the conventional rice plants under double-row pattern, which was only around one-third of the highest number of leaves in the aerobic rice plants, which was in the T3 treatment, but under the triple-row pattern, leaf number of the conventional rice was higher than that of the rice plants in the double-row pattern.

If we compare Fig. 1 and Fig. 2, it seems that the patterns of the interaction between the two treatment factors are slightly different. The average grain yield per clump in Fig. 2 is highest on the red rice plants in the T3 treatment under triple-row pattern, while leaf number per clump is highest on the red rice plants in the T3 treatment under double-row pattern. This means that the strongest determinant of the highest grain yield in the context of these treatments was not the highest leaf number at anthesis, as it can also be seen from Table 2 that the correlation coefficient with grain yield is only +0.590 , which is much lower than that of harvest index, which is +0.961 , although both are significant ( $\mathrm{p}$-value $<0.01$ ). 


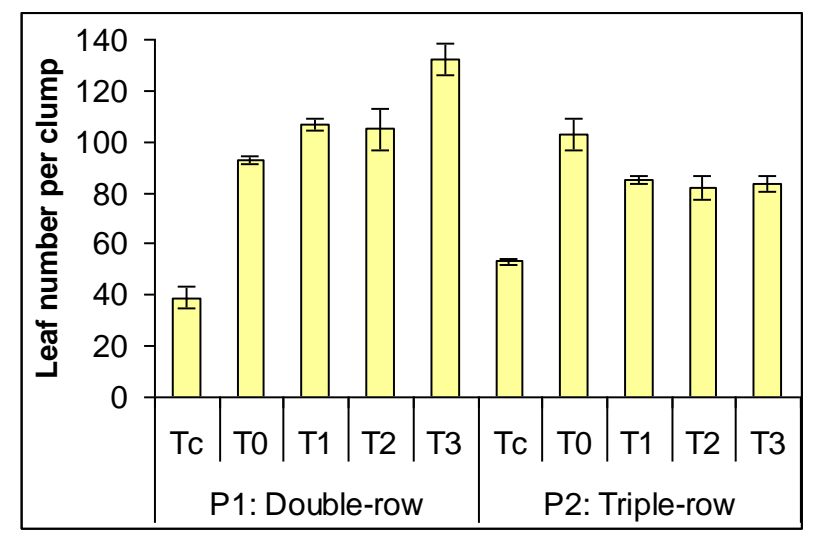

Fig.1: Interaction effects of the treatments on leaf number per clump

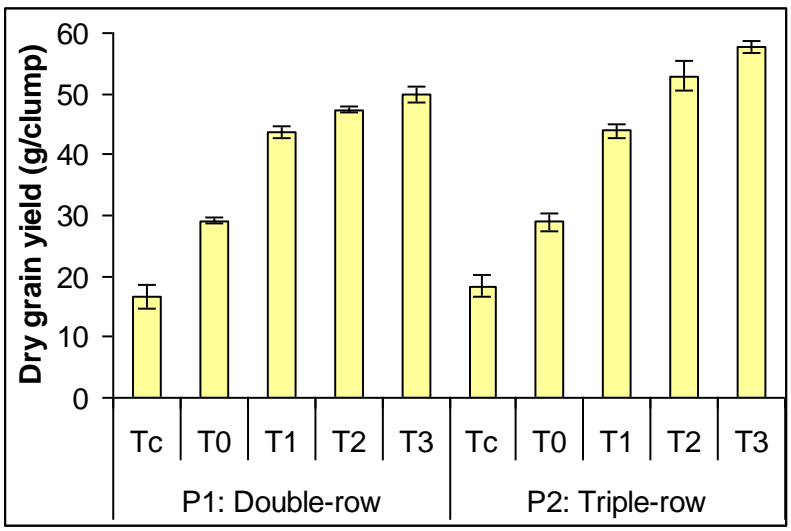

Fig.2. Interaction effects of the treatments on grain yield per clump

Based on the correlation coefficients in Table 2, it seems that the highest determinant for grain yield was harvest index, with an $\mathrm{R}^{2}=92.35 \%$. According the results of analysis by Sinclair and de Wit [12], seed plants require high supply of nitrogen during the seed-filling stage to maintain high photosynthate and nitrogen supply to the growing seeds for higher grain yield, and if nitrogen supply to the plants is lower than these requirements, then the plants will remobilize $\mathrm{N}$ content of the leaves, which accelerates leaf senescence and decreases grain yield. This means that rice plants also require higher $\mathrm{N}$ supplying capacity for higher rates of photosynthate production and partition to the growing seeds during the seed-filling stage.

It can also be seen from Fig. 3 that the average harvest index is highest on the red rice plants in the $\mathrm{T} 3$ treatment under triple-row pattern, followed by those in the T3 treatment under double-row pattern and those in $\mathrm{T} 2$ treatment under triple-row pattern. However, dry straw weight per clump and percentage of panicle to tiller number are much lower on the red rice plants in the T3 treatment of double-row pattern compared with on those in the $\mathrm{T} 3$ treatment of triple row pattern, but in contrast tiller number at anthesis was higher on the red rice plants in the $\mathrm{T} 3$ of double-row than in the T3 of triple-row pattern (Table 3). The lower dry straw weight (Table 3) coupled with lower harvest index (Fig. 3) and lower percentage of filled panicle number (Table 3) would logically result in lower grain yield per clump on the red rice plants in the T3 treatment under double-row than those in the $\mathrm{T} 3$ treatment under triple row pattern.

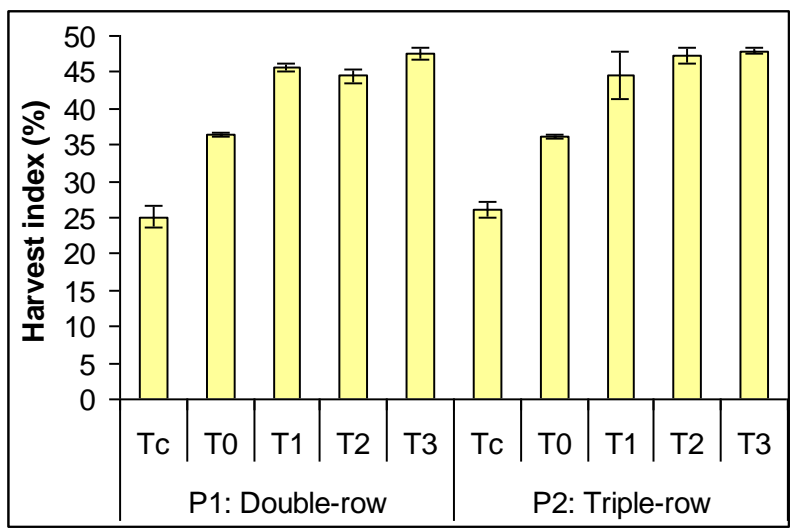

Fig.3. Average (Mean \pm SE) harvest index (\%) of red rice as affected by relay-planting soybean at different dates between double and triple rows of rice

Table 3: Mean straw dry weight, tiller number, panicle number, and \%-panicle number per clump

\begin{tabular}{lccccc}
\hline Row Patterns & Tech & $\begin{array}{c}\text { Straw dry } \\
\text { weight } \\
\text { (g/clump) }\end{array}$ & $\begin{array}{c}\text { Tiller } \\
\text { number } \\
\text { per clump }\end{array}$ & $\begin{array}{c}\text { Filled } \\
\text { panicle } \\
\text { number }\end{array}$ & $\begin{array}{c}\text { \%-panicle } \\
\text { number }\end{array}$ \\
\hline P1: Double-row & TC & 48.83 & 16.9 & 13.0 & 77.15 \\
& T0 & 50.95 & 23.9 & 15.3 & 64.25 \\
& T1 & 52.02 & 26.1 & 20.3 & 78.01 \\
& T2 & 59.35 & 26.1 & 22.3 & 85.46 \\
& T3 & 54.97 & 29.3 & 21.7 & 73.86 \\
\hline P2: Triple-row & TC & 51.77 & 17.0 & 15.0 & 88.06 \\
& T0 & 51.24 & 23.0 & 17.7 & 76.81 \\
& T1 & 55.30 & 24.3 & 21.7 & 89.29 \\
& T2 & 58.93 & 27.3 & 22.2 & 81.30 \\
& T3 & 62.64 & 27.3 & 21.7 & 79.27 \\
\hline
\end{tabular}

It could also be possible that competition between the red rice and soybean plants was started to occur in the double-row pattern due to higher number of soybean plants per plot and higher number of red rice leaves per clump when compared with those in the triple-row pattern, especially during the seed-filling stage (after anthesis). With higher number of leaves per clump, higher soybean population per bed, and closer planting distance between the red rice rows and soybean row would result in higher shading intensity imposed by the rice plants to the intercropped soybean plants, which in turn would result in lower rates of photosynthesis and $\mathrm{N}_{2}$ fixation by the 
soybean plants under double-row pattern than those under triple-row pattern. This is similar to the results reported by Wangiyana et al. [13] that relay-planting higher number of soybean or mungbean plants (i.e. three rows) between two rows of waxy maize plants resulted in lower grain yield of the waxy maize compared with relay-planting two rows of soybean or mungbean between two rows of waxy maize plants.

Many have reported that in an intercropping system, there was a significant $\mathrm{N}$-transfer from legume to cereal crops, such as from peanut to rice plants in an aerobic system [5], from peanut to maize plants [4], and from soybean to sorghum plants [6]. Wangiyana et al. [3] also reported that growing together in one pot with soybean under aerobic irrigation system resulted in much greener leaves on red rice plants at anthesis, especially on those inoculated with biofertilizer containing mixed species of Arbuscular Mycorrhizal Fungi (AMF). Several promising lines of red rice plants intercropped with soybean under aerobic irrigation systems on raised-beds were also reported to produce higher number of filled grains and grain yield per clump [7], which also infer higher biomass partitioning rates to seeds under intercropping with soybean compared with under monocropped red rice.

According to the results reported by Inal et al. [4], intercropping maize with peanut increased the availability of the nutrients in the rhizosphere of the intercropped plants compared with its monocrop, and this resulted in higher nutrient contents in the plants grown under intercropping system compared with under monocropping system. Therefore, it is clear why grain yield was higher on the red rice plants intercropped with soybean relayplanted at one, two or three weeks after seeding pregerminated seeds of the red rice, which was probably due to the higher $\mathrm{N}$ contents in the leaves of intercropped red rice compared with in the monocropped red rice plants. Higher leaf $\mathrm{N}$ content was also found on the red rice plants intercropped with peanut, especially when peanut was relay planted three weeks after seeding the red rice [9]. Arifuddin et al. [10] also reported that relay-planting legume crops, including peanut of Hypoma-3 variety, mungbean of Kenari variety, and soybean of Dering-1 variety, at three weeks after seeding red rice pregerminated seeds was found to result in the highest tiller number, panicle number, filled grain number, and grain yield per clump of the red rice plants grown together with those legume crops in pot culture under aerobic irrigation systems. Leaves of the red rice plants grown together with soybean in pot culture were also reported to be much greener than those growing in monocropped pots, at anthesis of the rice plants [3].

\section{CONCLUSION}

It can be concluded that intercropping red rice plants with soybean under aerobic irrigation system significantly increased grain yield compared with monocropped red rice either under aerobic or conventional systems, mostly due to higher panicle number per clump supported with higher harvest index of the rice plants intercropped with soybean especially when soybean was relay-planted at three or two weeks after seeding the pre-germinated seeds of the red rice.

\section{REFERENCES}

[1] Bouman, B.A.M. 2001. Water efficient management strategies in rice production. International Rice Research Notes, 26(2): 17-22.

[2] Prasad, R. 2011. Aerobic Rice Systems. Advances in Agronomy, 111: 207-247.

[3] Wangiyana, W., Aryana, I.G.P.M., Gunartha, I.G.E., and Dulur, N.W.D. 2018. Intercropping with soybean and inoculation with Arbuscular Mycorrhiza to increase panicle production of various promising lines of upland and amphibious red rice in aerobic system. Sem. Nas. Lingk. Lahan Basah, 3(2): 388-393. https://snllb.ulm.ac.id/prosiding/index.php/snllblit/article/view/86/84

[4] Inal, A., Gunes, A., Zhang, F., and Cakmak, I. 2007. Peanut/maize intercropping induced changes in rhizosphere and nutrient concentrations in shoots. Plant Physiology and Biochemistry, 45: 350-356.

[5] Chu, G.X., Shen, Q.R., and Cao, J.L. 2004. Nitrogen fixation and $\mathrm{N}$ transfer from peanut to rice cultivated in aerobic soil in an intercropping system and its effect on soil $\mathrm{N}$ fertility. Plant and Soil, 263: 17-27.

[6] Fujita, K., Ogata, S., Matsumoto, K., Masuda, T., OfosuBudu, G.K., and Kuwata, K. 1990. Nitrogen Transfer and Dry Matter Production in Soybean and Sorghum Mixed Cropping System at Different Population Density. Soil Sci. Plant Nutr., 36(2): 233-241.

[7] Wangiyana, W., Aryana, I.G.P.M., and Dulur, N.W.D. 2019. Increasing Yield Components of Several Promising Lines of Red Rice through Application of Mycorrhiza Bio-Fertilizer and Additive Intercropping with Soybean in Aerobic Irrigation System. International Journal of Environment, Agriculture and Biotechnology, 4(5): 1619-1624.

[8] Wangiyana, W., Aryana, I.G.P.M., and Dulur, N.W.D. 2020. Mycorrhiza biofertilizer and intercropping with soybean increase anthocyanin contents and yield of upland red rice under aerobic irrigation systems. Paper presented at the $7^{\text {th }}$ International Conference on Sustainable Agriculture and Environment (ICSAE-7), 25-27 August, 2020, Surakarta, Indonesia.

[9] Wangiyana, W., Farida, N., and Abdurrachman, H. 2020. Relay-planting of peanuts between double or triple rows at different dates increases growth, nitrogen content, and yield of red rice under aerobic irrigation systems. International Journal of Environment Agriculture and Biotechnology, 5(5): 1378-1382. 
[10] Arifuddin, Wangiyana, W., and Aryana, I.G.P.M. 2019. Effect of Relay-Planting Several Legume Species at Various Ages of Rice on Growth and Yield of Red Rice Grown Together with Legume Crops under Aerobic Irrigation System. International Journal of Environment, Agriculture and Biotechnology, 4(6): 1704-1710.

[11] Farida, N., Abdurrachman, H., Budianto, V.F.A., and Wangiyana, W. 2016. Growth Performance of Red Rice as Affected by Insertion of Peanut Row between Double and Triple-Rows of Rice in Aerobic System on Raised-Beds. Proceedings of the First International Conference on Sciences and Technology, 1-2 December, 2016, Mataram, Lombok-NTB, Indonesia. pp. 191-196. http://lppm.unram.ac.id/wp-content/uploads/2019/03/16.PROSIDING-FIRST-ICST-TAHUN-2016-Lengkap.pdf.

[12] Sinclair, T.R., and de Wit, C.T. 1975. Photosynthate and nitrogen requirements for seed production by various crops. Science, 189: 565-567.

[13] Wangiyana, W., Irwinsyah, L.R., Parawinata, and Kisman. 2020. Additive Intercropping with Legume Crops Increases Waxy Maize Yield on Vertisol Riceland in Lombok, Indonesia. Russian Journal of Agricultural and SocioEconomic Sciences, 102(6): 57-64. 